\title{
PENGARUH PEMBERIAN KURSUS CALON PENGANTIN (SUSCATIN) TERHADAP PENGETAHUAN KESEHATAN REPRODUKSI CATIN
}

\section{THE INFLUENCE OF GIVING FUTURE BRIDEGROOM COURSE TOWARD THE KNOWLEDGE OF REPRODUCTIVE HEALTHIN}

\author{
Ida Tri Yuliana ${ }^{1}$, Yuni Sulistiawati ${ }^{2}$, Riona Sanjaya $^{3}$, Nila Kurniasih ${ }^{4}$ \\ Fakultas Kesehatan Universitas Aisyah Pringsewu \\ e-mail :depriazza7@gmail.com
}

\begin{abstract}
The Influence Of Giving Future Bridegroom Course Toward The Knowledge Of Reproductive Healthin The Religious Affairs Office Of Pringsewu2019. The bride and groom as someone who will enter the gates of a marriage really needs information about reproductive health. Pre-survey data from Pringsewu regency in 2019 were 712 or $71.2 \%$, and still far from the target of $100 \%$. The research objectivewas to determine the influence of giving future bridegroom course toward the knowledge of reproductive healthin the religious affairs office of pringsewu2019.The design of this research was pre-experiment with one group pre-post-test design. The population in this research is future bridegroomwho registered on October in the religious affairs office of pringsewu2019. The population in this research was 21 bridegrooms. While the samples taken were 20 bridegrooms. The sampling technique in this study uses purposive sampling technique. Data analysis uses Univariate Analysis and Bivariate Analysis.Univariate calculation results note that the average value of the level of knowledge of respondents about reproductive health before attending the future bridegroom course is 58.25 in the medium category and after attending the bride and groom course is 75.00 in the Medium category. Bivariate analysis results obtained that the p-value 0,000 , because the p-value $0,000<\alpha$ $(0.05)$, it can be concluded that there is a significant influence on the level of knowledge about reproductive health of future bridegroom before and after being given future bridegroomcourse in the religious affairs office of pringsewu2019.From the results of the research above, the researchers suggest that this research to be an additional reference for future researchers with different variables.
\end{abstract}

Keywords:Future bridegroom course, the Knowledge of ReproductiveHealth, Future bridegroom

\begin{abstract}
Abstrak: Pengaruh Pemberian Kursus Calon Pengantin (Suscatin) Terhadap Pengetahuan Kesehatan Reproduksi Catin di Kantor Urusan Agama (Kua)Pringsewu Tahun 2019. Perkawinan adalah ikatan lahir dan batin antara seorang pria dan wanita sebagai suami istri dalam rangka membentuk pernikahan yang sehat secara reproduksi, dibutuhkan suatu informasi yang diperoleh saat mengikuti kursus calon pengantin. Kursus catin merupakan pemberian informasi penyuluhan tentang kesehatan reproduksi, namun saat ini target pencapaian tersebut masih kurang dari $100 \%$, khususnya di daerah pringsewu, cakupan kursus caten hanya sebesar $71,2 \%$ dari $100 \%$ pasangan caten pertahun2019. Tujuan Penelitian adalah mengetahui pengaruh pemberian suscatin terhadap pengetahuan kesehatan reproduksi catin di kantor urusan agama(KUA) pringsewu. Desainpenelitianiniadalahpre eksperimendenganrancangan one group pre test - post test.Populasi dalam penelitiaan ini adalah Catin yang mendaftar pada bulan oktober di KUA Pringsewu Tahun 2019sejumlah 21 orang. Sedangkan responden yang diambil sebanyak 20 calon pengantin. Teknik pengambilan sampel pada penelitian ini menggunakantekhnikpurposive sampling. Analisa data menggunakan Analisis Univariat dan Analisis Bivariat.Hasil Penghitungan univariat diketahui bahwa nilai rata-rata tingkat pengetahuan responden tentang kesehatan reproduksi sebelum mengikuti kursus calon pengantin adalah 58,25. Setelah mengikuti kursus calon pengantin adalah
\end{abstract}


75,00..Hasil analisis Bivariatdiperolehbahwa p-value 0,000, karena p-value 0,000< $\alpha(0,05)$ maka dapat disimpulkan bahwa ada pengaruh tingkat pengetahuan tentang Kesehatan reproduksi Catinse belum dan setelah diberikan kursus calon pengantin (Suscatin) di KUA Pringsewu.Dari hasil penelitian diatas peneliti menyarankan agarpenelitian ini menjaditambahanreferensiuntuk peneliti selanjutnyadenganvariable yang berbeda.

Kata Kunci : Kursus Calon Pengantin, Pengetahuan Kesehatan ReproduksiCalon Pengantin

\section{PENDAHULUAN}

Perkawinan adalah ikatan lahir dan batin antara seorang pria dan wanita sebagai suami istri dengan tujuan untuk membentuk keluarga (rumah tangga) yang bahagia.Kesehatan reproduksiadalah kesehatan secara fisik, mental, dan kesejahteraan sosial secara utuh pada semua hal yang berhubungan dengan sistim dan fungsi, serta proses reproduksi dan bukan hanya kondisi yang bebas dari penyakit dan kecacatan. Kesehatan reproduksi merupakan komponen penting kesehatan bagi pria maupun wanita, tetapi lebih di titik beratkan dan diutamakan pada wanita, karena lebih memiliki kebutuhan khusus yang berhubungan dengan fungsi seksualdan sistem reproduksi yang sensitif terhadap kerusakan yang dapat terjadi disfungsi atau penyakit (Yani, 2009).

Hak - hak reproduksi merupakan hak pria dan wanita untuk memperoleh informasi.Hak - hak tersebut diantaranya adalah hak untuk memperoleh pelayanan kesehatan yang memadai. Salah satu tujuannya dari kesehatan reproduksi sendiri adalah pelayanan kesehatan selama kehamilan sehingga ibu dapat melahirkan anak secara aman, serta memberikan kesempatan bagi para pasangan untuk memiliki bayi yang sehat, (Kusmiran,Eny.2012).

Calon pengantin sebagai seseorang yang akan memasuki gerbang pernikahan sangat memerlukan informasi tentang kesehatan reproduksi. Informasi perlu diberikan karena masih banyak anggapan yang salah tentang kesehatan reproduksi sehingga diperlukan informasi agar tidak salah perilaku dalam kesehatan reproduksi (Sriatmi A, Palimbo A. 2015). Untuk mensukseskan tujuan tersebut pemerintah mengeluarkan kebijakan dengan menerbitkan buku saku bagi catin yang berisi tentang kespro dan seksual guna menambah ilmu pengetahuan tentang kespro dan seksual dalam persiapan kehamilan, dan mengeluarkan Permenkes RI No.97 Tahun 2014 melalui badan penasehat, pembinaan, dan pelestarian pernikahan (BP4) menyelenggarakan kursus calon pengantin (suscatin), namun mereka belum memahami tentang kesesehatan reproduksi maka dilakukan suscatin ini agar catin lebih memahami kesehatan reproduksinya yang tertuang didalam buku saku.

Data prasurvei bimbingan perkawinan (BIMWIN) sekitar 149ribu pasang pengantin seluruh Indonesia tahun 2017, jumlah pasangan yang mendapatkan BIMWIN masih jauh dari jumlah peristiwa nikah yang terjadi(linmas DKI ). Data dari prasurvei kabupaten pringsewu tahun 2018 sebanyak 3500 pasang pengantin hanya $87 \%$ yang mendapatkan bimbingan perkawinan. Untuk kecamatan pringsewu tahun2018 sebanyak 662 pasang pengantin atau 66,2\%, angka tersebut mengalami kenaikan tahun 2019 sebanyak 712 atau 71,2 \%, tetapi masih jauh di bandingkan dengan target $100 \%$ pasanganharus mendapat bimbingan perkawinan dan juga pengetahuan kesehatan reproduksi(KUA Pringsewu).

Dari hasil penelitian Riantini efektivitas penyuluhan kesehatan reproduksi pada calon pengantin di puskesmas pucang sewu surabaya tahun 2017. Hasil dari penelitian menunjukkan sebelum penyuluhan terdapat $62,5 \%$ responden memiliki pengetahuan kurang, setelah dilakukan penyuluhan, responden yang memiliki pengetahuan kurang menjadi $12,5 \%$. Sebelum penyuluhan nilai rata-rata responden adalah 50,62 dan kemudian meningkat menjadi 66,25 setelah penyuluhan. Hasilnya bahwa ada efektivitas perubahan sebelum dan sesudah penyuluhan kesehatan reproduksi pada

$$
\text { https://ejournal.umpri.ac.id/index.php/JIK } \mid \mathbf{1 4}
$$


catin.Berdasarkan uraian diatas maka penulis tertarik untuk meneliti tentang "Pengaruh Pemberian Kursus Calon Pengantin (Suscatin) terhadap pengetahuan kesehatan reproduksi catin di kantor urusan agama (KUA) pringsewu tahun 2019"

\section{METODE}

Jenis penelitian yang digunakan dalam penelitian ini adalah penelitiankuantitatif, penelitian kuantitatif merupakan salah satu jenis penelitian yang spesifiknya adalah sistematis, terencana dan terstruktur dengan jelas sejak awal hingga pembuatan desain penelitiannya. Menurut(sugioyono,2013), metode penelitian kuantitatif dapat diartikan sebagai metode penelitian yang berlandaskan pada filsafat positivisme, digunakan untuk meneliti pada populasi atau sample tertentu, tekhnik pengambilan sample pada umum nya dilakukan secara random, pengumpulan data menggunakan instrument penelitian, analisis data bersifat kuantitatif/statistik dengan tujuan untuk menguji hipotesis yang telah di tetapkan.

Penelitian ini menggunakan pendekatan pre eksperimen one group pre test-post tes, menurut (Sugiyono, 2012) adalah suatu teknik untuk mengetahui efek sebelum dan sesudah pemberian perlakuan.Waktu penelitian dilaksanakan febuari 2020. Tempat penelitian di KUA Pringsewu, Kecamatan Pringsewu, Kabupaten Pringsewu.Menurut (Notoatmodjo, 2010) mengartikan populasi keseluruhan objek penelitian atau objek yang diteliti.Populasi dalam penelitiaan ini adalah Catin yang mendaftar pada bulan oktober di KUA Pringsewu tahun 2019, Kecamatan Pringsewu, Kabupaten Pringsewu.Populasipada penelitianini sejumlah 21 orang calon pengantin.

Sampel adalah objek yang diteliti dan diaggap mewakili seluruh populasi (Notoatmodjo, 2010).Sampel dalam penelitian ini adalah catin yang mendaftar di KUA Pringsewu tahun 2019.Peneliti menentukan jumlah sampel minimal yang dapat diambil dalam penelitian ini, adapun metode statistik yang digunakan untuk menentukan besar sampel adalah :

$$
\mathrm{n}=\frac{\mathrm{N}}{1+\mathrm{N}\left(\mathrm{d}^{2}\right)}
$$

Keterangan :

$\mathrm{N}$ = Jumlah populasi

$\mathrm{n}=$ Besar Sampel

$\mathrm{d} \quad=$ presisi mutlak (tingkat kesalahan); 0,05

(SoekidjoNotoatmodjo,2010)

Berdasarkan rumus tersebut diatas, maka besarnya sampel penelitian yang digunakan dalam penelitian ini adalah sebagai berikut :

$\mathrm{n}=21=21 \quad \begin{array}{ll}21 \\ 1+20\left(0,05^{2}\right)\end{array}$
$1+0,05$


Hasil dari pengolaan data populasi diatas dapat disimpulkan bahwa untuk jumlah sampel pada penelitian ini adalah 20 orang.Dalam hal ini yang dimaksud dengan banyak adalah populasi.Pengambilan sampel, dimana sampel yang diambil adalah sampel yang benar-benar berprestasi atau yang mewakili seluruh populasi.Pada penelitian ini untuk pengambilan sampel menggunakan tekhnikpurposive sampling.Purposive sampling adalah pengambilan sampel yang berdasarkan atas suatu pertimbangan tertentu yang sifat-sifat populasi ataupun ciri-ciri yang sudah diketahui sebelumnya (Notoatmojo, 2010).

Sampel adalah sebagian yang diambil dari keseluruhan obyek yang diteliti dan dianggap mewakili seluruh populasi (Soekidjo Notoatmojo, 2010).

Kriteria inklusi dalam penelitian ini adalah :

Catin yang mengikuti bimbingan di KUA, Catin menikah Usia 19 Tahun, Kriteria Eksklusi adalah sebagian subyek yang memenuhi kriteria inklusi tetapi harus dikeluarkan karena suatu hal.Kriteria eksklusi dalam penelitian ini adalah :Responden yang memenuhi kriteria inklusi namun tidak bersedia berpartisipasi dalam penelitian. Tidak hadir di suscatin Variabel Penelitian

Menurut (Sugioyono,2013)Variabeladalahsesuatu atribut atau sifat atau nilai dari orang, obyek atau kegiatan yang mempunyai variasi tertentu yang di tetapkan oleh peneliti untuk dipelajari dan kemudian ditarik kesimpulan. Variabel ini terdiri dari :

Independent Variabel/Variabel bebas sering disebut variabel stimulus, prediktor, antecedental adalah variable yang mempengaruhi atau yang menjadi sebab perubahannya atau tibulnya variable dependen (terikat)(Sugioyono, 2013). Variabel bebas penelitian ini adalah suscatin.

\section{Dependen Variabel}

Variabel dependen/terikat yang sering disebut variabeloutput, krteria, konsenkuen adalah variable yang dipengaruhi atau yang menjadi akibat karena adanya variable bebas (Sugioyono, 2013) Variabel terikat dalam penelitian ini adalah pengetahuan catin tentang kesehatan reproduksi.

Analisis Univariat

Analisis univariatbertujuan untuk mejelaskan atau mendeskripsikan karakteristik setiap variable penelitian (Notoatmojo, 2010).

\$rumus :

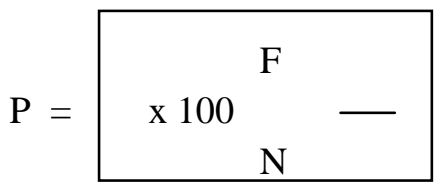

Keterangan :

$\mathrm{P}=$ Persentase

$\mathrm{F}=$ Jumlah responden yang menjawab benar

$\mathrm{N}=$ Jumlah sampel

Analisis Bivariat

UjiNormalitas Data

Uji normalitas data digunakan untuk mengetahui sampel yang digunakan berasal dari populasi yang sama atau data berdistribusi normal atau tidak. Alat analisis yang digunakan untuk menguji normalitas data adalah dengan uji Shapiro-Wilk. Sampel berdistribusi normal apabila asymptotic 
sig $>0,05$, sebaliknya dikatakan tidak normal apabila asymptotic sig $<0,05$. Pengujian ini menggunakan program SPSS. Jika hasil pengujian menunjukkan sampel berdistribusi normal maka uji beda yang akan digunakan dalam penelitian ini adalah uji parametric (Paired Samples T-test). Tetapi apabila sampel tidak berdistribusi normal maka uji beda yang akan digunakan dalam penelitian ini adalah ujinon parametric (Wilcoxon Sign Test). (Santoso,2016).

\section{Uji Beda Dua Rata-Rata(Paired SampleT-Test)}

Analisis bivariat adalah analisis yang dilakukan terhadap dua variable yang diduga berhubungan atau berkorelasi.Pada penelitian inivariable yang digunakan uji T-paired sampleadalah Informasi Kesehatan Reproduksi dengan pengetahuan catin tentang kesehatan reproduksi di KUA Pringsewu.Menurut Widianto (2013), paired sample $t$ - test merupakan salah satu metode pegujian yang digunakan untuk mengkaji keefektifan perlakuan, ditandai adanya perbedaan rata - rata sebelum dan rata - rata sesudah diberikan perlakuan dan menggunakan program SPSS.Dasar pengambilan keputusan untuk menerima atau menolak (Ha) pada uji ini adalah sebagai berikut, Jika $\alpha<0,05$, maka Ha diterima, dan jika $\alpha>0,05$ maka Ha ditolak.

\section{HASIL}

Pengumpulan data dilakukan pada bulan febuari 2020 dengan responden sejumlah 20 responden.Dari hasil penelitian yang dilaksanakan dengan menggunakan kuesioner, didapatkan data penelitian yang telah diolah dan disajikan secara sistematis sebagai berikut:

\section{Analisis Univariat}

Nilai Rata-Rata Tingkat Pengetahuan Catin Tentang Kesehatan Reproduksi Sebelum Mengikuti Suscatin

Tabel 4.1 Nilai Rata-Rata Tingkat Pengetahuan Catin Tentang Kesehatan Reproduksi Sebelum Mengikuti Suscatin di KUA Pringsewu Tahun 2020

\begin{tabular}{lcccc}
\hline \multicolumn{1}{c}{ Ketegori } & Nilai Mean & SD & SE & N \\
\hline $\begin{array}{l}\text { Tingkat Pengetahuan Sebelum } \\
\text { Mengikuti Suscatin }\end{array}$ & 58.25 & 13.502 & 3.019 & 20 \\
\hline
\end{tabular}

Berdasarkan tabel 4.1 diketahui bahwa nilai rata-rata tingkat pengetahuan responden tentang kesehatan reproduksi sebelum mengikuti suscatin di KUA Pringsewu adalah 58,25. Nilai Rata-Rata Tingkat Pengetahuan Catin Tentang Kesehatan Reproduksi Setelah Mengikuti Suscatin

Tabel 4.2 Nilai Rata-Rata Tingkat Pengetahuan Catin Tentang Kesehatan Reproduksi Setelah Mengikuti Suscatin di KUA PringsewuTahun 2020

\begin{tabular}{lcccc}
\hline \multicolumn{1}{c}{ Ketegori } & $\begin{array}{c}\text { Nilai } \\
\text { Mean }\end{array}$ & SD & SE & N \\
\hline $\begin{array}{l}\text { Tingkat Pengetahuan } \\
\text { Setelah Mengikuti Suscatin }\end{array}$ & 75.00 & 8.429 & 1.885 & 20 \\
\hline
\end{tabular}


Vol 10 No 1 Januari 2021 | Page 13-22

Berdasarkan tabel 4.1 diketahui bahwa nilai rata-rata tingkat pengetahuan responden tentang kesehatan reproduksi setelah mengikuti suscatin di KUA Pringsewu adalah 75,00.

Analisis Bivariat

Uji Normalitas

Tabel 4.3 Uji Normalitas Pengetahuan Tentang Kesehatan Reproduksi Catin Sebelum dan Setelah Pemberian Kursus Calon Pengantin (Suscatin) KUA Pringsewu Tahun 2020

\begin{tabular}{lcccccc}
\hline \multirow{2}{*}{ Variabel } & \multicolumn{3}{c}{ Kolmogorov-Smirnov } & \multicolumn{3}{c}{ Shapiro-Wilk } \\
\cline { 2 - 7 } & Statistic & Df & Sig. & Statistic & df & Sig. \\
\hline $\begin{array}{l}\text { Pengetahuan sebelum pemberian } \\
\text { kursus calon pengantin (Suscatin) }\end{array}$ & 0,245 & 20 & 0,003 & 0,913 & 20 & 0,74 \\
$\begin{array}{l}\text { Pengetahuan setelah pemberian kursus } \\
\text { calon pengantin (Suscatin) }\end{array}$ & 0,223 & 20 & 0,010 & 0,905 & 20 & 0,050 \\
\hline
\end{tabular}

Berdasarkan hasil uji normalitas ditemukan nilai shapiro-wilk setelah pemberian kursus calon pengetantin (Suscatin) 0,050 dengan nilai alpa 5\% atau 0,05, maka nilai p-value $>0,050$ artinya terdapat pengaruh yang signifikan tingkat pengetahuan tentang kesehatan reproduksi Catin sebelum dan setelah diberikan kursus calon pengantin (Suscatin) di KUA Pringsewu.

Pengaruh Pemberian Kursus Calon Pengantin (Suscatin) Terhadap Pengetahuan Kesehatan Reproduksi Catin

Tabel 4.4 Uji Beda Mean Pengetahuan Tentang Kesehatan Reproduksi Catin Sebelum dan Setelah Pemberian Kursus Calon Pengantin (Suscatin) KUA Pringsewu Tahun 2020

Paired Samples Test

\begin{tabular}{|c|c|c|c|c|c|c|c|c|}
\hline & \multicolumn{5}{|c|}{ Paired Differences } & \multirow{3}{*}{$\mathrm{t}$} & \multirow{3}{*}{ df } & \multirow{3}{*}{ Sig. (2-tailed) } \\
\hline & \multirow[t]{2}{*}{ Mean } & \multirow{2}{*}{$\begin{array}{c}\text { Std. } \\
\text { Deviation }\end{array}$} & \multirow{2}{*}{$\begin{array}{c}\text { Std. Error } \\
\text { Mean }\end{array}$} & \multicolumn{2}{|c|}{$\begin{array}{c}95 \% \text { Confidence Interval } \\
\text { of the Difference }\end{array}$} & & & \\
\hline & & & & Lower & Upper & & & \\
\hline $\begin{array}{cc}\text { Pair } 1 & \begin{array}{c}\text { Sebelum - } \\
\text { Sesudah }\end{array}\end{array}$ & -16.750 & 13.791 & 3.084 & -23.204 & -10.296 & -5.432 & 19 & 0.000 \\
\hline
\end{tabular}

Berdasarkan tabel 4.4diketahui bahwa nilai t hitung sebesar -5,432 dengan p-value 0,000, karena p-value $0,000<\alpha(0,05)$ maka dapat disimpulkan bahwa ada pengaruh tingkat pengetahuan tentang kesehatan reproduksi Catin sebelum dan setelah diberikan kursus calon pengantin (Suscatin) di KUA Pringsewu.

\section{PEMBAHASAN}

\section{Univariat}

Pengetahuan Calon Pengantin sebelum mengikuti kursus calonpengantinTingkat pengetahua nresponden menggambarkan sejauh mana responden mengetahui tentang kesehatan reproduksi.Semakin tinggip engetahuan responden maka semakin tinggi pula kesadaran mereka 
tentang pentingnya kesehatan reproduksi. Dari hasil penelitian pada tabel 4.1 diperoleh bahwa pengetahuan sebelum mengikuti suscatin adalah 58,25.

Menurut Budiman \& Agus (2013) salah satu faktor yang mempengaruhi pengetahuan adalah adanya informasi (buku saku catin) baru mengenai sesuatu hal memberikan landasan kognitif baru bagi terbentuknya pengetahuan terhadap hal tersebut

Penelitian ini sejalan dengan penelitian yang dilakukan oleh Rahim R, dkk (2013) kursus calon pengantin tentang kesehatan reproduksi dapat meningkatkan pengetahuan responden sebesar 29,6\% dan sikap responden meningkat sebesar $81,5 \%$.

Berdasarkanhasil penelitian bahwa suscatin dapat meningkatkan pengetahuan tentang kesehatan reproduksi calon pengantin di KecamatanPringsewu. Respondendi KUA Pringsewu masih banyak yang belum memahami tentang makna dari kursus calon pengantin yang diselenggarakan bila dilihat dari sudut pandang pendidikan dan pekerjaanya.

Pengetahuan Calon Pengantinsesudah mengikuti kursus calon pengantin. Setelah mengikuti suscatin di KUA Pringsewu, nilai rata-rata tingkat pengetahuan responden mengalami peningkatan. Dari hasil pada tabel 4.2 diperoleh bahwa nilai rata-rata pengetahuan sesudah mengikuti suscatin adalah 75,00.Pengetahuan tidakhanyabisa diperoleh melalui pendidikan formal tetapibisa melalui informasi dari rekanyang berlatar belakangkesehatan, ataupun darimedia massa, karena pengetahuan bukan hanya dari keyakinan atau kepercayaan individu melainkan suatu usaha untuk mencaritahu, atau melalui pengalaman pribadi bersama orang lain. Menurut Jumail bahwa bimbingandan konseling akan berhasil baik menurut kompetensi konselor.Oleh karena itu kompetensi yang memadai seorang konselor mempunyai peranan terhadap peningkatan pengetahuan sesuai dengan apa yang diinginkan, hal tersebut berdampak terhadap peningkatan kemampuan responden. Perubahan pegetahuan calon pengantinsangat ditentukan oleh factor konselor inovatif dan kreatif dalam membangun komunikasi yang baik dengan kliennya, misalnya membuat modul konseling, penggunaan media yang sesuaidan alat komunikasi yang baik serta penguasaan informasi pengetahuan dan teknologi sangat perlu.

Hasil penelitianlainyangmendukungadalahpenelitianyangdilakukanolehRiantini (2018) di puskesmas pucang sewu surabaya,diperolehbahwapenelitian menunjukkan sebelum penyuluhan terdapat $62,5 \%$ responden memiliki pengetahuan kurang, setelah dilakukan penyuluhan, responden yang memiliki pengetahuan kurang menjadi $12,5 \%$. Sebelum penyuluhan nilai rata-rata responden adalah 50,62 dan kemudian meningkat menjadi 66,25 setelah penyuluhan.

Berdasarkan perbandingan hasil penelitian bahwa tingkat pengetahuan calon pengantin diKecamatan Pringsewu dipengaruhi oleh pemberian kursus calon pengantin. Hal ini dibuktikanpadasaat dilakukan penelitian, dari sebagian responden (calon pengantin) nilai rata-rata pengetahuan sebelum mengikuti suscatin adalah 58,25dan nilai rata-rata pengetahuan sesudah mengikuti suscatin adalah 75,00. Berdasarkan peningkatan sebelum dan sesudah diberikan suscatin mengalami peningkatan dengan selisih nilai sebesar 16,75.Selainitu, tingkat pendidikancalon pengantin juga berpengaruh pada saat dilakukan kegiatan ini, diketahui pada saat peneliti melakukans urvei, maka sebagianbesar calon pengantin yang memiliki tingkat pendidikan tinggi (diploma dan sarjana) lebih mudah dalam menjawab pertanyaan-pertanyaan yang diajukan setelah dilakukan kursus pengantin.

\section{Bivariate}

Uji Normalitas

Hasil uji normalitas ditemukan nilai setelah pemberian kursus calon pengetantin (Suscatin) 0,050 dengan nilai alpa $5 \%$ atau 0,05 , maka nilai p-value $>0,050$ artinya terdapat pengaruhtingkat

$$
\text { https://ejournal.umpri.ac.id/index.php/JIK| } 19
$$


pengetahuan tentang kesehatan reproduksi Catin sebelum dan setelah diberikan kursus calon pengantin (Suscatin) di KUA Pringsewu.

Uji normalitas data digunakan untuk mengetahui sampel yang digunakan berasal dari populasi yang sama atau data berdistribusi normal atau tidak. Sampel berdistribusi normal apabila asymptotic sig $>0,05$, sebaliknya dikatakan tidak normal apabila asymptotic $\operatorname{sig}<0,05$.

Berdasarkan hasil Uji diatas bahwa uji normalitas perlu dilakukan untuk menyimpulkan suatu data tersebut normal atau tidak normal. Uji normal ini dilakukan untuk menentukan metode dalam mengolah data koesioner. Hasil dari Uji normalitas menyatakan data tersebut normal, maka peneliti menggunakan metode paired sample $t$ - test. Pengaruh Pemberian Kursus Calon Pengantin (Suscatin) Terhadap Pengetahuan Kesehatan Reproduksi CatinHasil Perhitungan statistik diperoleh bahwa nilai t hitung sebesar $-5,432$ dengan p-value 0,000 , karena p-value $0,000<\alpha(0,05)$ maka dapat disimpulkan bahwa ada pengaruh tingkat pengetahuan tentang kesehatan reproduksi Catin sebelum dan setelah diberikan kursus calon pengantin (Suscatin) di KUA Pringsewu.

Suscatin adalah suatu kegiatan untuk meningkatkan pengetahuan calon pengantin dengan pemberian suscatin melalui media buku saku yang diberikan selama 2 jam, yang berisikan tentang: Akad/janji nikah yang di ucapkan atas nama Tuhan Yang Maha Esa yang merupakan awal dari kesepakatan bagi calon pengantin untuk saling memberi ketenangan (sakinah) dengan mengembangkan hubungan atas dasar saling cinta dan kasih.Masalah kesehaatan reproduksi, misalnya masalah pergaulan bebas pada remaja, kehamilan remaja, aborsi yang tidak aman, kurangnya informasi tentang kesehatan reproduksi. Pemeriksaan fisik juga perlu dilakukan dalam persiapan pranikah meliputi tanda-tanda vital, pemeriksaan darah rutin, golongan darah, gula darah, dan tidak kalah pentingnya yaitu pemeriksaan status gizi dan status Imunisasi. Meskipun banyak hal yang berpengaruh terhadap pengetahuan tentang kesehatan reproduksi baik calon pengantin laki-laki dan perempuan tetap mempunyai hak yang sama untuk memperoleh pengetahuan yang tepat dan seluas-luasnya. Sehingga dalam membina rumah tangga yang baik tidak hanya sekedar meneruskan tradisi, akan tetapi benar-benar dilandasi oleh suatu ilmu pengetahuan yang luas dan tepat sehingga terwujudlah keluarga yang sehat dan bertanggung jawab.

Penelitian ini sejalan dengan penelitian Nita Evrianasari (2017) di Kantor Urusan Agama (KUA) Tanjung Karang Pusat, diperoleh bahwa Ada pengaruh pemberian buku saku kesehatan reproduksi dan seksual terhadap pengetahuan catin tentang reproduksi dan seksual pada catin diKantor Urusan Agama(KUA) Tanjung Karang Pusat Tahun 2017 dengan nilai p-value = 0,000.

Berdasarkan hasil perhitungan di atas bahwa dengan adanya pelaksanaan Kursus Calon Pengantin ini sangat mempengaruhi pengetahuan para Calon Pengantin karena adanya bekal yang diperoleh setelah di kursus. Hal ini dibuktikan dengan hasil nilai P yang menunjukkan bahwa ada pengaruh tingkat pengetahuan tentang kesehatan reproduksi Catin di KUA Pringsewu.Jika peserta suscatin masih perlu bimbingan lebih lanjut maka pihak keluarga yang mengantar diharuskan memberikan materi tambahan sesuai dengan catatan yang diberikan oleh petugas.

\section{SIMPULAN}

Jumlah responden adalah 20 orang dengan nilai rata-rata tingkat pengetahuan responden tentang kesehatan reproduksi sebelum mengikuti suscatin di KUA Pringsewu adalah 58,25. Nilai rata-rata tingkat pengetahuan responden tentang kesehatan reproduksi setelah mengikuti suscatin di KUA Pringsewu adalah 75,00. Hasil Perhitungan statistik diperoleh bahwa p-value 0,000, karena p-value

https://ejournal.umpri.ac.id/index.php/JIK $\mid 20$ 
$0,000<\alpha(0,05)$ maka dapat disimpulkan bahwa ada pengaruh tingkat pengetahuan tentang kesehatan reproduksi Catin sebelum dan setelah diberikan kursus calon pengantin (Suscatin) di KUA Pringsewu.

\section{SARAN}

Diharapkan penelitian ini dapat bermanfaat bagi Universitas Aisyah Pringsewu yaitu mendapatkan informasi tentang pelaksanaan suscatin lanjutan disuatu daerah tertentu. Bagi KUA Pringsewu agar dapat memberikan kursus secara online dimasa pandemik, dan penelitian ini bisa dijadikan sebagai tambahan referensi untuk melakukan penelitianselanjutnya dengan variableyang berbeda yang berkaitan dengan pelaksanaan pemberian suscatin lanjutan.

\section{DAFTAR PUSTAKA}

Agus, Riyanto dan Budiman.(2013). Kapita Selekta Kuisioner Pengetahuan dan Sikap Dalam Penelitian Kesehatan.Jakarta : Salemba Medika

Arikunto.(2010). Metodologi Penelitian Suatu Pendekatan Proposal.Jakarta : PT. Rineka Cipta

Arikunto, S. (2014).Prosedur Penelitian Suatu Pendekatan Praktis. Jakarta : Rineka Cipta.

Dewi, PHC \& Notobroto, HB 2014 'Rendahnya Keikutsertaan Pengguna Metode Kontrasepsi Jangka Panjang Pada Pasangan Usia Subur', Jurnal Biometrika dan Kependudukan, Surabaya, Vol. 3, No. 1, diakses 27 Juli 2018.

Hastono, P. S. (2012). Statistik Kesehatan. Edisi VI. Jakarta : PT. Raja Grafindo Persada.

Kemendikbud. (2012). Pengembangan Kurikulum 2013, Jakarta: Kementrian Pendidikan dan Kebudayaan

Kusmiran,Eny. (2012). Kesehatan Reproduksi Remaja dan Wanita. Jakarta:salemba Medika (PP 1)

Mubarak, Wahid Iqbal.(2012) Promosi Kesehatan Untuk Kebidanan, Jakarta: salemba medika

Nita Evrianasari. (2017). Pengaruh BukuSakuKesehatan Reproduksi DanSeksualBagi Catin Terhadap PengetahuanCatin Tentang Reproduksi DanSeksual. Jurnal Kebidanan. Vol 3, No 4, Oktober 2017: 211-216

Notoatmodjo, S. (2010).Metodologi Penelitian Kesehatan. Jakarta : Rineka Cipta.

Notoatmodjo,S. (2012). Metodologi Penelitian Kesehatan. Jakarta: Rineka Cipta.

Notoatmodjo, S. (2014).Ilmu Perilaku Kesehatan. Jakarta: Rineka Cipta

Rahim, R., A.R Thaha, Citrakesumasari. (2013). Pengetahuan dan Sikap Wanita Prakonsepsi Tentang Gizi dan Kesehatan Reproduksi Sebelum dan Setelah Suscatin di Kecamatan Ujung Tanah. Jurnal MKMI. 1-15

Riantini Amalia PS. (2018) Efektifitas Penyuluhan Kesehatan Reproduksi pada Calon Pengantin di Puskesmas Pucang Sewu Surabaya Jurnal Biometrika dan Kependudukan.;7:29-38.

Santoso, Singgih. (2016). Panduan Lengkap SPSS Versi 23.Jakarta : Elekmedia Computindo.

https://ejournal.umpri.ac.id/index.php/JIK $\mid 21$ 


\section{(Jik) JURNALLUMAR KESESHATAN}

Vol 10 No 1 Januari 2021 | Page 13-22

Sriatmi A, Palimbo A. (2015). Pelaksanaan Sistem Rujukan Kasus Ibu Hamil Risiko Tinggi oleh Bidan Desa ke Puskesmas Poned tahun 2015.Jurnal Manajemen Kesehatan Indonesia. April 2015 volume 3;01(10)41-51

Sugiyono.(2012).Metode Penelitian Bisnis.Bandung : Alfabeta

Sugiyono. (2013). Metode Penelitian Kuantitatif, Kualitatif dan R\&D. Bandung: Alfabeta.CV

Widiyanto, M.A. (2013). Statistika Terapan, Konsep dan Aplikasi SPSS/Lisrel dalam Penelitian Pendidikan, Psikologi dan Ilmu Sosial Lainya.Jakarta : PT Elex Media Komputindo.

Yani.W,Anita .R danYuliasti.EP(2009).Kesehatan Reproduksi.Jakarta:Fitramaya

. (1974). Undang-Undang Republik Indonesia Nomor 1 Tahun 1974 tentang Perkawinan.Jakarta (tidak diterbitkan).

(2019). Kantor Urusan Agama Kecamatan Pringsewu.

(2015). Kesehatan Reproduksi dan Seksual bagi Calon Pengantin. - Jakarta: Kementrian Kesehatan RI. 